\section{British psychiatric morbidity survey}

\author{
R. JENKINS, P. BEBBINGTON, T. S. BRUGHA, M. FARRELL, G. LEWIS \\ and H. MELTZER
}

There is mounting evidence of the massive global health burden of mental illness (Murray \& Lopez, 1996; Jenkins, 1997). Within Great Britain, the Department of Health's overall objectives for mental illness were summarised as follows (Department of Health, 1993):

(a) To reduce the incidence and prevalence of mental disorders.

(b) To reduce the mortality associated with mental disorders.

(c) To reduce the extent and severity of other problems associated with mental disorders, for example:

(i) poor physical health;

(ii) impaired social functioning;

(iii) poor social circumstances;

(iv) family burden.

(d) To ensure appropriate services and interventions are provided.

(e) To reverse the public's negative perception of mental illness, for example:

(i) counter fear, ignorance and stigma;

(ii) create a more positive social climate in which to seek help;

(iii) improve quality of life for people with mental health problems.

(f) To research causes, consequences and care of specific mental disorders.

Within these overall objectives, England's Health of the Nation strategy (Department of Health, 1992) set specific targets for reducing morbidity and mortality, and laid out a tripartite framework for action: improving information and understanding about mental illness, developing local comprehensive services, and developing good practice.

As part of the agenda to improve information and understanding about mental illness, the Department of Health commissioned the Office of Population, Censuses and Surveys (now renamed the
Office of National Statistics) to survey psychiatric morbidity of the country in collaboration with an advisory group of psychiatric epidemiologists.

The purpose of this paper is to provide a short overview of the survey programme to date as a whole. Details of the background to the survey programme and of each of the studies can be found elsewhere (Jenkins et al, 1997a,b; Bebbington et al, 1998).

\section{RATIONALE}

The survey was commissioned by the Department of Health for England, together with the Welsh Office and the Scottish Home and Health Department, to give a national picture of the prevalence, severity and duration of mental health and their accompanying disability (and thereby to give a baseline measure of the Health of the Nation target to improve the health and social functioning of people with mental illness); associated risk factors; and the extent to which health and social care needs are met by services. This is the first national survey in any country to collect data on prevalence, risk factors and associated disability simultaneously in household, institutional and homeless samples by use of standardised assessment techniques. The survey covered neuroses, affective disorders, psychoses, alcohol and drug misuse. A survey of individuals held in custody is underway, and a survey of children and adolescents is being commissioned. It is planned to include the elderly when the adult survey is repeated in a few years time. The Department of Health has also commissioned a psychiatric study within the Fourth National Survey of Ethnic Minorities.

As well as providing a baseline for the Health of the Nation targets, the survey data were intended to inform those who commission services of local needs and to inform the Government of national needs. Furthermore, the core methodology can now be used by people wishing to do a more intensive local survey.

\section{METHOD}

\section{Sampling strategy}

Four separate surveys have been completed to date. The first was a private household survey, with the small users 'postcode address files' as the sampling frame, sampling 90 random delivery points in each of 200 postal sectors. It was stratified by regional health authority (giving 18000 delivery points in order to yield 10000 subjects). The second was an institutional survey, selecting randomly from lists of hospitals and residential homes from the Department of Health and lists of hostels and group home obtained from health and local authorities, stratified by institutional size. The third was a supplementary sample of people with known psychosis living in households, carried out in order to provide additional information on service use. It was obtained by random samples from a listing of everyone with known psychosis compiled by general practitioners (GPs) and country mental health teams in the same 200 postal sectors. The fourth was a survey of homeless and roofless people sampled from lists of homeless people given temporary housing in private sector leased accommodation from hostels for the homeless, from night shelters and from people sleeping rough who were in contact with day centres. A one in 10 pilot of each survey was carried out before embarking on the main stage.

\section{Interviewing strategy}

All responders in the household were interviewed by Office of Population Censuses and Surveys Social Survey interviewers using the Revised Clinical Interview Schedule (CIS-R; Lewis et al, 1992) leading to ICD-10 (World Health Organization, 1992) diagnostic categories; a psychosis screening questionnaire specifically developed for the survey; questions about alcohol and drug misuse and dependence using quality/frequency questions from the regular national surveys of alcohol and tobacco consumption; questions about stressful life events, social support, social disability, activities of daily living, education and employment; and questions about long-standing illness and medication. Those subjects scoring over 12 on the CIS-R and/or 
positive on the Psychosis Screening Questionnaire (Bebbington \& Nayani, 1995) were asked further detailed questions on use of health, social and voluntary care services and informal care, and were given a Schedules for Clinical Assessment in Neuropsychiatry (SCAN; Wing et al, 1990) assessment by psychiatrists trained in its use to provide a one-year prevalence.

In the Institutional Survey, the same procedure was carried out, except that proxy information was sought for those who were unable to cooperate with the interview. In the supplementary sample, all were approached for a SCAN interview. In the hostels and private sector leased accommodation, a similar procedure to that in the household survey was followed, with the addition of the 12-item General Health Questionnaire (GHQ; Goldberg, 1972). Pilot studies indicated that a shorter questionnaire was needed for the sample from night shelters and day centres. The 12 -item GHQ therefore replaced the CIS-R and briefer questions on the social environment and use of services were added in night shelters and day centres.

\section{RESULTS}

\section{Household survey}

\section{Neurosis}

The household survey achieved a response rate of $80 \%$. One in six adults aged 16-64 years who live in private households had suffered from some type of neurotic disorder in the week before the survey interview, half of which was mixed anxiety depression. All types of neurotic disorders were more common among women than men (see Table 1). Marital status was strongly associated with neurotic disorder: rates were substantially higher in separated, divorced and widowed individuals of both genders and among cohabiting women. Unemployed people were about twice as likely to suffer neurotic disorders compared with people in work; those living in urban settings 1.5 times as likely to suffer them than rural dwellers. Table 2 shows the socio-demographic associations of a raised total CIS-R score based on multiple logistic regression analysis. About half of individuals identified as having a neurotic disorder also suffered from long-standing physical complaints, compared with only $30 \%$ of people with a neurotic disorder. This differential was seen across all ages and both genders. Furthermore, individuals
Table 1 Prevalence of psychiatric disorders per 1000 population in adults aged 16-64 years, in Great Britain 1993

\begin{tabular}{lrrr}
\hline & Women & Men & All adults \\
\hline Rate per thousand in past week (s.e.) & & & \\
Mixed anxiety and depressive disorder & $94(5)$ & $54(4)$ & $77(3)$ \\
Generalised anxiety disorder & $34(3)$ & $28(2)$ & $31(2)$ \\
Depressive episode & $25(2)$ & $17(2)$ & $21(1)$ \\
Phobias & $14(2)$ & $7(1)$ & $11(1)$ \\
Obsessive-compulsive disorder & $15(2)$ & $9(2)$ & $12(1)$ \\
Panic disorder & $9(1)$ & $8(2)$ & $8(1)$ \\
Any neurotic disorder & $195(7)$ & $123(5)$ & $160(5)$ \\
Rate per thousand in past 12 months (s.e.) & & & $4(1)$ \\
Functional psychosis & $4(1)$ & $4(1)$ & $47(3)$ \\
Alcohol dependence & $21(2)$ & $75(5)$ & $22(2)$ \\
Drug dependence & $14(2)$ & $29(3)$ & \\
\hline
\end{tabular}

Tabie 2 Odds ratios (OR) of socio-demogr aphic correlates of Revised Clinical Interview Schedule (CIS-R) score

\begin{tabular}{|c|c|c|}
\hline CIS-R score of 12 or more & Adjusted OR & $95 \%$ Confidence interval \\
\hline \multicolumn{3}{|l|}{ Gender } \\
\hline Male & 1.00 & - \\
\hline Female & $1.56^{* *}$ & $1.37-1.78$ \\
\hline \multicolumn{3}{|l|}{ Age (years) } \\
\hline $16-24$ & 1.00 & - \\
\hline $25-34$ & 1.07 & $0.87-1.32$ \\
\hline $35-44$ & 1.23 & $0.99-1.53$ \\
\hline $45-54$ & 1.24 & $0.99-1.55$ \\
\hline $55-64$ & $0.72^{* *}$ & $0.56-0.91$ \\
\hline \multicolumn{3}{|l|}{ Family unit type } \\
\hline Couple, no children & 1.00 & - \\
\hline Couple: I+ children & 1.03 & $0.87-1.21$ \\
\hline Lone parent+child & $1.56^{* *}$ & $1.26-1.93$ \\
\hline One person only & $1.48 * *$ & $1.25-1.76$ \\
\hline Adult with parents & 0.76 & $0.54-1.05$ \\
\hline Adult with one parent & 0.80 & $0.54-1.19$ \\
\hline \multicolumn{3}{|l|}{ Employment status } \\
\hline Working full time & 1.00 & - \\
\hline Working part time & 1.19 & $1.00-1.42$ \\
\hline Unemployed & $2.26^{* *}$ & $1.87-2.72$ \\
\hline Economically inactive & $1.7 I^{* *}$ & $1.47-2.00$ \\
\hline \multicolumn{3}{|l|}{ Accommodation } \\
\hline Detached & 1.00 & - \\
\hline Semi-detached & 0.96 & $0.80-1.15$ \\
\hline Terrace & 1.19 & $1.00-1.43$ \\
\hline Flat/maisonette & 1.15 & $0.93-1.43$ \\
\hline \multicolumn{3}{|l|}{ Tenure } \\
\hline Owner/occupier & $1 / 00$ & - \\
\hline Renter & $1.33^{* *}$ & $1.16-1.53$ \\
\hline \multicolumn{3}{|l|}{ Locality } \\
\hline Semi-rural/rural & 1.00 & - \\
\hline Urban & $1.21 * *$ & $1.06-1.38$ \\
\hline
\end{tabular}

$* * 0<0.01$. 
with neuroses were twice as likely as those without to have consulted their GP in the fortnight before interview. However, onequarter of those with a neurotic disorder had not consulted any professional about their mental health, usually because they thought no one could help.

Subjects with significant depressive symptoms were asked about suicidal ideas. Just under $1 \%$ of the total sample in the household survey reported suicidal thoughts in the preceding week, two-thirds of them women.

Only one-fifth of those reporting suicidal ideas were receiving antidepressant medication and one-sixth were receiving counselling or psychotherapy.

\section{Alcohol and drug use}

One adult in 20 had experienced symptoms of alcohol dependence in the preceding year and one in 40 dependence on drugs. Men were over three times as likely as women to be dependent on alcohol and twice as likely to be dependent on drugs. Alcohol dependence was nearly twice as common among those who were unemployed as with those who were working; drug dependence was over five times more frequent among unemployed people.

\section{Psychosis}

The overall prevalence of psychosis in the household survey was four per 1000 , with that for urban dwellers being twice that for those living in the country. Of people with psychosis, two-thirds were in touch with specialist services, while $18 \%$ had seen only their GP in the year before interview and a further $18 \%$ claimed never to have sought professional help. There is therefore significant unmet need for specialist support for people with psychosis.

\section{Social disability}

The levels of social disability found in the household survey, not only in people with psychosis but also in those with neurosis,

Table 4 Prevalence of psychiatric disorders by economic activity (s.e.)

\begin{tabular}{lcccc}
\hline All & $\begin{array}{c}\text { Working } \\
\text { full time }\end{array}$ & $\begin{array}{c}\text { Working } \\
\text { part time }\end{array}$ & Unemployed & $\begin{array}{c}\text { Economically } \\
\text { inactive }\end{array}$ \\
\hline $\begin{array}{l}\text { Neurosis rate per } 1000 \text { in past } \\
\text { week }\end{array}$ & $118(6)$ & $160(10)$ & $259(17)$ & $212(10)$ \\
$\begin{array}{l}\text { Psychosis rate per } 1000 \text { in past } \\
12 \text { months }\end{array}$ & $2(1)$ & $5(2)$ & $7(2)$ & $9(2)$ \\
$\begin{array}{c}\text { Alcohol dependence rate per } \\
1000 \text { in past } 12 \text { months }\end{array}$ & $54(4)$ & $42(6)$ & $89(13)$ & $29(4)$ \\
$\begin{array}{l}\text { Drug dependence rate per } 1000 \\
\text { in past } 12 \text { months }\end{array}$ & $13(2)$ & $17(4)$ & $83(12)$ & $23(3)$ \\
\hline
\end{tabular}

and in the group who were experiencing suicidal thoughts, is astonishingly high (see Table 3) and emphasise the need for integrated assessment and management of health and social care needs.

\section{Associated socio-demographic variables}

The household survey demonstrated a significant relationship of unemployment with psychiatric disorder and of marital status (single, separated, divorced, widowed had higher rates) and of living status (single parents with children had double the rates), flagging up the need for purchasers to take these variables into account when assessing health needs (see Table 4).

\section{Institutional survey}

The survey of adults living in institutions covered those aged 16 to 64 years who were permanently resident in institutions catering for people with mental health problems in Great Britain. Residents were defined as permanently resident if they had been living in the sampled establishment for six months or more, or had no other permanent address, or were likely to stay in the establishment for the foreseeable future. In 1994, abour 33200 adults aged 16-64 years were permanently resident in accommodation of this type.

Seventy per cent of residents for whom diagnoses were obtained suffered from

Table 3 Difficulties in activities of daily living (ADL) in household samples

\begin{tabular}{lcc}
\hline Subject group & \% with any ADL difficulties & Base \\
\hline Suicidal thoughts in past week & 50 & 80 \\
Psychosis in past year & 40 & 44 \\
Neurosis in past week & 32 & 1557 \\
None of the above & 12 & 8184 \\
\hline
\end{tabular}

schizophrenia, delusional and schizoaffective disorders, $8 \%$ from neuroses, and $8 \%$ from affective psychoses. The distribution of the disorders varied according to whether the setting was a hospital or residential accommodation. The prevalence of schizophrenia and related disorder was higher in hospitals $(74 \%$ compared with $67 \%$ in residential accommodation), while neurotic disorders were more prevalent among those in residential accommodation (12\% compared with $4 \%$ in hospital). The majority of residents with schizophrenia and related disorders had a length of stay of two years or more, with a median length of stay of 2.5 years. Residents with affective psychoses showed similar lengths of stay. Conversely, most residents with neurotic disorders had a length of stay of less than two years with a median length of stay of 1.5 years.

\section{Psychiatric morbidity among homeless people}

The Office of Population Censuses and Surveys' survey of psychiatric morbidity among homeless people covered a broad range of people who do not have adequate shelter, they were defined according to their accommodation circumstances: residents of hostels, of private sector leased accommodation, of night shelters, and of homeless people sleeping rough and using day centres.

The prevalence of neurosis was $38 \%$ among hostel residents, $35 \%$ among private sector leased accommodation residents, $60 \%$ among night shelter residents, and $57 \%$ among homeless people sleeping rough (compared with $14 \%$ in private households). The prevalence of psychosis was $8 \%$ among hostel residents, $2 \%$ among private sector leased accommodation residents and was not estimated in night shelter 
residents and people sleeping rough (compared with $0.4 \%$ in private households). The prevalence of alcohol dependence was $16 \%$ among hostel residents, $3 \%$ among private sector leased accommodation residents, $44 \%$ among night shelter residents and $50 \%$ among homeless people sleeping rough (compared with $5 \%$ of private household residents).

The prevalence of drug dependence was $6 \%$ in hostel residents on non-cannabinoid drugs, with a further $5 \%$ dependent on cannabis only, $22 \%$ of night shelter residents were dependent on non-cannabinoid drugs rising to $29 \%$ when cannabis was included. In people sleeping rough, $12 \%$ were dependent on non-cannabinoid drugs rising to $24 \%$ when cannabis was included.

\section{IMPLICATIONS}

The surveys demonstrated a number of significant findings which need to be taken into account in the planning and delivery of mental health services in Great Britain. The very high prevalence of neurosis, some of which is extremely severe and associated with suicidal risk, means proper attention must be given to the education and training of primary care teams about mental health (Jenkins, 1992), to the primary/secondary care interface (Strathdee \& Jenkins, 1996), to supporting primary care teams with good practice guidelines (Department of Health, 1997), agreed criteria for referral, and with shared care where appropriate. It is clear also that the prevention and early detection and amelioration of the more common and less severe forms of neurosis will need to be addressed more widely in schools, workplaces and in other community settings (Jenkins \& Üstün, 1998). This will require systematic effort by developers and evaluators of preventive interventions. The regional variation in psychosis and the association of mental disorders with sociodemographic factors such as unemployment and living conditions mean that these variables must be taken into account when assessing health needs and when allocating financial resources.

The high levels of social disability associated not only with psychosis, but also

RACHEL JENKINS, FRCPsych, PAUL BEBBINGTON, FRCPsych, TRAOLACH S. BRUGHA. MRCPsych, MIKE FARRELL, MRCPsych, GLYN LEWIS. MRCPsych, HOWARD MELTZER. PhD. WHO Collaborating Centre. Institute of Psychiatry. London

Correspondence: Dr R. Jenkins. WHO Collaborating Centre, Institute of Psychiatry. De Crespigny Park. Denmark Hill. London SE5 8AF. Tel: 0171740 5293; Fax: 0171919 3669; e-mail: r.jenkins @iop.bmf. ac.uk

(First received II December 1997, final revision 26 March 1998, accepted 24 March 1998)

with neurosis mean that individuals must receive proper integrated assessment of the social needs as well as their health needs, and that care plans must address social disability as well as health issues in an integrated way.

The high rates of suicidal thoughts in the household survey in people with depression mean that teaching good suicidal assessment and management techniques to health and social care professionals must be a priority (Jenkins et al, 1994) as should the national and local action to minimise environmental risk factors for suicide.

The high levels of morbidity in the homeless must be addressed by purchasing of services for the homeless in every locality to ensure adequate primary and secondary care.

More important than any of the individual findings is the achievement of a representative baseline framework of information on the mental health of our nation and the associated health care response to this, as described by users of the National Health Service in Great Britain. By repeating the survey programme in furure years it will be possible to monitor and estimate the extent to which the objectives for mental health prevention and treatment services can be more accurately based. By doing so, attention can be given both to common mental disorders and to severe mental illness by means of specific, well informed mental health policies.

\section{REFERENCES}

Bebbington, P. E. \& Nayani, T. (1995) The Psychosis

Screening Questionnaire. Internotional journol of Methods in Psychiotric Reseorch, 5, 11-20.

_, Dunn, A., Jenkins, R., ef al (1998) The influence of age and sex on the prevalence of depressive conditions: Report for the National Survey of Psychiatric Morbidity. Psychologicol Medicine. 28. 9-19.
Department of Health (1992) The Health of the Notion - a Strotegy for Heoith in Engiand. London: HMSO.

- (1993) The Public Health Informotion Strategy Improving Informotion on Mental Heolth. London: Department of Health.

- (1997) The Primary Mentol Health Care Toolkit. London: Department of Health.

Goldbers, D. P. (1972) The Detention of Psychiatric Iliness by Questionnaire (GHQ). Maudsley Monograph 21. London: Oxford University Press.

Jenklns, R. (1992) Developments in the primary care of mental illness - a forward look. Internotional Review of Psychiotry, 4, 237-242.

- (1997) Reducing the burden of mental illness. Loncet. 349. 1340 .

_, Griflth, S., Wylie, l., at al (1994) The Prevention of Suicide. London: HMSO

_, Bebbington, P., Brugha, T., et ol (1997o) The National Psychiatric Morbidity Surveys of Great Britain - strategy and methods. Psychologicol Medicine. 27. 765-774.

- , _, ef of (1997b) The National Psychiatric Morbidity Surveys of Great Britain - initial findings from the Household Survey. Psychological Medicine, 27. 775-789.

- Üxtin, T. B. (eds) (1998) Preventing Mental Illness - Mental Health Promotion in Primory Care. Chichester: Wiley.

Lewis, G., Polosi, A. J., Araya, R., ot of (1992) Measuring psychiatric disorder in the community: a standardised assessment for use by lay interviewers. Psychologicol Medicine. 22, 465-486.

Mann, A. H., Tylee, A. \& Jenkins, R. (eds) (1998) Mental health and primary care - implications for policy. International Review of Psychiotry, in press.

Murray J. L. \& Lopex, A. D. (1996) The Globol Burden of Diseose. Boston: World Health Organization. Harvard. World Bank

Strathdee, C. \& Jenkins, R. (1996) Purchasing mental health care for primary care. In Commissioning Mentol Health Services (eds G. Thornicroft \& G. Strathdee). London: HMSO.

Wing, J. K., Babor, T., Brugha, T., et of (1990) SCAN: Schedules for Clinical Assessment in Neuropsychiatry. Archives of Generol Psychiotry, 47, 589-593.

World Haalth Organization (1992) The Tenth Revision of the Internotional Clossification of Diseases and Reloted Heolth Problems (ICD-10). Geneva: WHO. 